\title{
AlHEAMENTO ELEITORAL: \\ REFLEXÕES SOBRE O SIGNIFICADO \\ DE VOTOS EM BRANCO, VOTOS NULOS \\ E ABSTENÇÕES NA TEORIA POLÍTICA CONTEMPORÂNEA
}

\author{
Paola Novaes Ramos ${ }^{1}$
}

\begin{abstract}
Resumo
0 presente artigo tem como objetivo analisar o impacto de votos em branco, votos nulos e abstenções sobre a legitimidade das democracias contemporâneas com auxílio do pensamento de alguns autores clássicos da teoria política contemporânea do final do século XX (especificamente, alguns autores liberais e alguns de seus críticos). Considerando que eleições são centrais e caracterizam boa parte das atuais democracias ocidentais, mesmo que não monopolizem a política como um todo, interessa saber qual é o significado desses fenômenos "não-decisórios" para os atuais sistemas de representação, com foco nas interpretações de Giovanni Sartori, Seymour Lipset, Samuel Huntington, Gabriel Almond e Sidney Verba, de um lado, e Carole Pateman, C. B. Macpherson e Pierre Bourdieu, de outro.
\end{abstract}

Palavras-chave: Eleições. Democracia. Participação política.

\footnotetext{
${ }^{1}$ A autora é graduada e mestre em Ciência Política pelo Instituto de Ciência Política da Universidade de Brasília. Foi professora de Ciência Política na Universidade de Brasília e no Instituto de Ensino Superior de Brasília. Atualmente, é aluna do programa de Doutorado do Centro de Estudos, Pesquisa e Pós-Graduação sobre as Américas, no Instituto de Ciências Sociais da Universidade de Brasília, e realizou pesquisa na área de teoria do Estado e modelos ibéricos de Estado Nacional durante 0 ano de 2008 junto à Universidade de Barcelona, Espanha.
} 


\title{
ELECTORAL INDIFFERENCE: REFLECTIONS ON THE \\ Significance of Blank votes, Null Votes and Abstentions in Contemporary Political Theory
}

\begin{abstract}
The present article analyses the impact of blank and annulled votes and electoral abstention upon the legitimacy of representative democracies with the help of some classic contemporary political theory authors of the end of the 20th century (specifically liberal authors and their critics). Considering elections are central to present day western democracies, even if they do not overtake politics as a whole, the goal is to understand the meaning of such "non-decisional" events to nowadays representative systems with special emphasis in the interpretations of Giovanni Sartori, Seymour Lipset, Samuel Huntington, Gabriel Almond and Sidney Verba on one side, and Carole Pateman, C.B. Macpherson and Pierre Bourdieu on the other.
\end{abstract} Keywords: Elections. Democracy. Political participation.

\section{AlHeamento Eleitoral: UMA CATEgoria FUNDAMENTAL EM RESULTADOS}

0 presente artigo agrupa votos em branco, votos nulos e abstenções na mesma categoria, denominada alheamento eleitoral, e observa tal fenômeno à luz do pensamento de autores importantes para a teoria política contemporânea. Esta categoria objetiva construir uma generalização baseada no resultado das ações não-participativas, ainda que cada um dos três fenômenos (votos em branco, votos nulos e abstenções) possa ter motivações diferentes. Além disso, o alheamento eleitoral, como generalização, precisa ser contextualizado em cenários e situações empíricas específicas para que seu poder explicativo torne-se mais claro de acordo com as situações que se pretende analisar. Os autores utilizados para interpretar os fenômenos dialogam dentro de um escopo de inspiração liberal ou de crítica a essa linha de percepção política, e em geral referem-se a sistemas eleitorais de voto facultativo, apesar deste ponto, relevante no debate político brasileiro ${ }^{2}$, não seja especificamente problematizado pelos autores

\footnotetext{
${ }^{2}$ A questão do voto facultativo é longamente discutida no Brasil, onde ainda se adota uma legislação de voto obrigatório, como vários países sul-americanos que vivenciaram regimes autoritários, ou países com problemas de disputa de nacionalidade, como a Bélgica, por exemplo. Contudo, os sistemas eleitorais e as conjunturas políticas de resultados eleitorais não são objeto do presente artigo. 
em questão. Embora exista ampla discussão no Brasil e alhures sobre a questão do alheamento eleitoral, inclusive fenômenos de abstenção política em massa em países como Portugal, por exemplo, busca-se observar os princípios de tais ações e as interpretações dos autores clássicos escolhidos.

0 debate acerca da participação política é incontestavelmente muito mais amplo do que a questão da participação eleitoral. Vários autores clássicos da literatura internacional, que trabalham com a participação política latu sensu, comoAlessandro Pizzorno (1975), RobertPutnam (1997), AlbertHirschman (1985), Phillipe Breton (2006), entre muitos outros, e da literatura nacional, como Fábio Wanderley Reis (1984), Leonardo Avritzer (1999; 2007) e Wanderley Guilherme dos Santos (1989; 1992; 1998), também entre muitos outros, são reconhecidamente importantes para o debate acadêmico, mas não serão trabalhados neste artigo em função da escolha por observar a literatura internacional da segunda metade do século XX. Quatro pensamentos mais conservadores (de Giovanni Sartori, Seymour Lipset, Samuel Huntington, e em conjunto, Gabriel Almond e Sidney Verba) e três pensadores críticos (Pateman, Macpherson e Bourdieu) foram escolhidos. Joseph Schumpeter, possivelmente pioneiro ao problematizar a não-participação voluntária de cidadãos no processo eleitoral, será abordado apenas na discussão sobre Carole Pateman, que critica longamente sua proposta schumpeteriana pelo fato do autor não ver na participação restrita um problema, e sim uma chave positiva e crucial para a manutenção do sistema representativo (algo que Pierre Bourdieu também diagnostica, porém com enfoque crítico, em seu trabalho $\mathrm{La}$ Distinction, abordado no presente artigo).

0 intuito da construção da categoria albeamento eleitoral, portanto, não é esgotar realidades de ausência de participação política, e sim fornecer uma ferramenta conceitual a ser utilizada como ponto de partida para a análise de situações eleitorais concretas, a partir do pensamento de alguns clássicos da teoria política contemporânea. Sistemas e legislações eleitorais de países que adotam democracias representativas tampouco serão analisados, em função natureza eminentemente teórica do artigo.

\section{A construÇC̃̃o dA CATEGoria}

0 primeiro pressuposto da categoria alheamento eleitoral é que a política, por mais que seja sempre motivada por interesses e valores (sendo composta, então, de dimensões subjetivas), é eminentemente prática, ou seja, ligada à ação. Os resultados da política são sempre motivados por algum valor, mas as 
consequiências dos atos políticos nem sempre correspondem às intenções dos agentes (CHISHOLM, 1998). 0 segundo pressuposto surge justamente deste caráter prático da política: tanto o depósito de votos válidos quanto o alheamento eleitoral são comportamentos, ou seja, ações sociais, e não apenas estados de consciência ou intenções. Por fim, o terceiro pressuposto é que intenções e resultados não são sinônimos (sendo os comportamentos ligados a resultados). Desta forma, por mais que as motivações de cada fenômeno que compõe o alheamento eleitoral sejam diferentes entre si (votos nulos geralmente são associados a protesto, votos em branco, a indiferença, e abstenções, a repúdio aos candidatos, conteúdos ou sistema, ou ao comodismo), o impacto do comportamento de distanciar da legitimidade do sistema representativo é o mesmo para as três formas de ação (ou, mais precisamente, três formas de inação).

Esclarecida a categoria, a discussão problematiza os fundamentos da legitimidade, que são diretamente ligados à crença e à aceitação populacional da comunidade política, do Estado, do regime, do sistema, e do governo (LEVI, 1996). A legitimidade é, desta forma, qualitativa, pois depende dos valores da população, e quantitativa, pois requer que a maior parte das pessoas - parcela significativa e majoritária desta população - aceite as estruturas da organização política.

Ao se compreender os fundamentos gerais da legitimidade, é possível observar mais precisamente as formas com as quais ela se manifesta. No fundo, legitimidade política é inversamente proporcional ao grau de conflito entre população e Estado. Quanto mais aceitação, menos questionamento. Contudo, em sociedades complexas, existem diferentes formas de se questionar a ordem estabelecida, e resta saber se 0 alheamento eleitoral pode ou não ser uma forma de questionamento. Mais precisamente, se ele seria uma forma politicamente eficaz de questionamento popular, ou seja, se e como atinge a legitimidade do sistema representativo (em uma escala gradativa, é preciso saber que nível da estrutura política está sendo questionado, desde o elemento mais vulnerável ao mais estruturado, ou seja, desde a legitimidade do governo, mais passível de questionamento, passando pela legitimidade do sistema e do regime adotado, até chegar à legitimidade da comunidade política e do Estado).

\section{Democracia E LEGITIMIDADE}

"Democracia" é um conceito que permeia tanto os imaginários sociais quanto as instituições políticas ocidentais. No fundo, a idéia de democracia está principalmente vinculada a mecanismos de igualdade e ampla participação. 
Somada a princípios do republicanismo e do liberalismo a partir do século XVI, que associam a política de Estados à idéia de soberania nacional (que supõe, entre outras chaves, apoio formal da população eleitora ao Estado e ao governo), a democracia contemporânea acabou se tornando algo bastante complexo após a reivindicação de ampliação das regras formais que antes contemplavam apenas a classe masculina pagadora de impostos para a quase totalidade da população dos países que adotam tal sistema (SARTORI, 1996).

Partindo do pressuposto que toda ação social tem finalidades (regidas por intenções), mecanismos (regidos pela racionalidade em interação com o cenário social) e resultados (regidos pela realidade, determinando o sucesso ou o fracasso da ação), a política democrática ideal seria aquela onde há o bem comum como fim, mecanismos de participação popular para alcançá-lo, e resultados que correspondam satisfatoriamente a este fim almejado ${ }^{3}$. Dentre esses elementos, porém, o que se sobressai na idéia de democracia é o mecanismo de participação (mais precisamente, o acesso direto ou indireto da população às decisões públicas). Dependendo do grau de acesso às decisões públicas, o cidadão está mais ou menos vinculado à política.

Sartori afirma que os vários tipos de arranjos institucionais para participação política diferenciam-se, basicamente, pelo número de relações intermediárias entre o cidadão e a questão política. Analisando a democracia direta, o referendo, o plebiscito e a democracia representativa, podemos encontrar os seguintes formatos:

Democracia direta: cidadão $\rightarrow$ questão política

A democracia direta não determina hierarquias entre os participantes. Sua natureza é horizontal, e seu instrumento é a assembléia (típica de Atenas na Grécia Antiga nos séculos IV e V a.C.). Em democracias diretas, os participantes debatem e decidem sem intermediários ${ }^{4}$. Uma das características mais importantes das assembléias é que elas só são operacionalmente possíveis se existe um número reduzido de pessoas participando5.

\footnotetext{
${ }^{3}$ Para mais detalhes sobre esta abordagem de fins, meios e resultados, ver Cohn (1979).

${ }^{4}$ A ausência de intermediários está na decisão pública, mas existiam, nessas assembléias, delegações de poder de fala a oradores em momentos de dissidência. Ver Finley (1985).

5 Segundo Finley (1978), na Grécia Antiga, o número de participantes na Pnyx era de aproximadamente 6.000 cidadãos.
} 
Democracia por referendo: cidadão $\rightarrow$ instrumento do sistema político $($ referendo $) \rightarrow$ questão política

Democracia por plebiscito: cidadão $\rightarrow$ instrumento do sistema político (plebiscito) $\rightarrow$ questão política

0 referendo e o plebiscito são arranjos possíveis independente do tamanho da população. Eles são instrumentos democráticos que conferem a decisão ou aval diretamente ao povo. Porém, nestes dois arranjos, a população tem o poder de decidir sobre a questão política, mas não tem acesso ao debate ou formulação da questão. Elas são dadas, previamente estabelecidas e fornecidas ao votante. No referendo, existe a possibilidade aprovar ou vetar uma decisão governamental. Geralmente ele ocorre como instrumento de legitimação à decisão, onde o poder do participante resume-se a aval, veto ou abstenção. Já o plebiscito pode oferecer mais de três opções e é ponto de partida (muitas vezes, poupando os representantes de arcar com o ônus da decisão). Uma grande diferença entre referendo e plebiscito é que o referendo é uma ratificação de decisões prévias, e em plebiscitos não existem diretrizes de decisões a priori (embora sempre existam diretrizes de discursos).

Democracia representativa: cidadão $\rightarrow$ instrumento do sistema político (eleição de candidatos) $\rightarrow$ representante $\rightarrow$ questão política

A democracia representativa possibilita um grau relativo de participação em populações maiores, como as que se agregaram a partir da fundação do Estado Moderno, e se ampliam com o advento do sufrágio universal nos Estados contemporâneos. Neste arranjo institucional, existem dois intermediários entre a questão política e o cidadão. A decisão pública não é do cidadão comum, pois quem lida com ela é o representante (em populações de centenas de milhões de pessoas, este arranjo é operacional, enquanto a democracia direta não é). 0 voto popular apenas elege pessoas (não decide diretamente), e não aceita nem refuta questões políticas concretas.

Após observar os arranjos institucionais da democracia, é importante entender as definições de legitimidade. A legitimidade é a base de qualquer autoridade política democrática, e sua natureza está na formação de consenso, construindo aceitação popular do poder político. A legitimidade expressa-se de várias formas, mas sinteticamente, pode-se dizer que em um país com dominação racional-legal (WEBER, 1999) que adote democracias eleitorais possui legitimidade geral e a legitimidade específica (LEVI, 1996). A legitimidade geral corresponde à condução da política com base nos valores de racionalidade e 
legalidade. A legitimidade específica, por vez, trata das justificativas, dos discursos, dos contextos e dos rumos da política, ou seja, depende do que a população acredita (se ela acredita nas prerrogativas de Estado, em sua comunidade política, no governo eleito, no regime). A legitimidade específica se funda e transita em um eixo de consenso, que assegura a obediência mínima (legitimidade geral), de um lado, e a adesão, que é o máximo de apoio que um governo pode ter, do outro.

A legitimidade é, portanto, um eixo com duas extremidades opostas de manifestação de consenso, sustentada por seu extremo legal (legitimidade geral) e seu extremo de adesão popular. Especificamente no caso das eleições, o fato delas ocorrerem normalmente, e de existir rodízio de representantes nas posições de poder, contempla a legitimidade geral ${ }^{6}$. 0 fato de haver alheamento eleitoral, portanto, insere-se nas complexidades da legitimidade específica.

De acordo com Richard Flathman (1996), conceder legitimidade atualmente é o mesmo que delegar a outros o direito reservado a nós mesmos de conduzir a própria vida e os eventos ligados a ela. Segundo este autor, as bases clássicas de legitimidade do Estado nunca foram problemáticas enquanto eram interpretadas como reflexos da providência divina, de atributos naturais e de ordenamentos ontológicos. Nestes casos, apenas um governo por parte dos "naturalmente inferiores" era considerado ilegítimo. 0 questionamento e a tematização da legitimidade ganharam força a partir do século XVII, com a crescente racionalização da vida humana e com o argumento de que qualquer tipo de governo ou autoridade requer uma justificativa. Desde então, toda autoridade passou a ser problemática (exceto a autoridade individual), e a delegação de poder foi intimamente conectada à autorização racional.

\section{FORMAS ELEITORAIS DE MANIFESTAÇÃO POPULAR EM DEMOCRACIAS REPRESENTATIVAS: VOTOS VÁLIDOS E ALHEAMENTO ELEITORAL}

Segundo Albert Hirschman, um dos problemas da ampliação do sufrágio é o monopólio da legitimidade do voto. 0 voto popular seria uma forma reduzida de ação política, que acaba tornando o cidadão comum politicamente fraco, pois ele está isolado e diluído em milhões de outras pessoas formalmente iguais ${ }^{7}$. Nesta

\footnotetext{
${ }^{6}$ Para uma idéia mais profunda sobre cumprimento das regras do jogo, ver Dahl (1997).

${ }^{7}$ Hirschman (1983) utilizou, como forma de ilustrar este argumento, a pintura de um homem
} 
linha de pensamento, Richard Flathman (1996) afirma que os cidadãos comuns têm duas escolhas: ou obedecem aos comandos, ou desligam-se da associação política. Ele cita uma terceira opção, conhecida como "desobediência passiva" ou "civil", na qual o comportamento é de submissão pacífica e interiormente 0 cidadão encontra-se em estado de insatisfação e rebeldia, mas está limitado pelo monopólio da legitimidade do voto.

Uma vez que democracias representativas contemporâneas caracterizam-se por eleições regulares de representantes, o processo eleitoral possui dois resultados preliminares: o montante de votos válidos, e o montante de votos brancos, nulos e abstenções. Essas duas esferas diferenciadas apresentam, no entanto, alguns pontos em comum:

1) Ambas são expressas de forma quantitativa (em números ou porcentagens);

2) Ambas variam contextualmente, dependendo dos cenários e das circunstâncias das eleições;

3) A esfera de votos válidos está dividida entre o número de votos para cada candidato, partido ou lista, enquanto

4) A esfera de votos em branco, votos nulos e abstenções é um somatório destes três elementos.

Por alheamento eleitoral entende-se a manifestação, em uma eleição, de indivíduos que não escolhem um representante político para exercer o poder. A categoria alheamento eleitoral tenta, então, definir uma dimensão obscura na política. Ela denuncia a falência de determinada parcela do eleitorado em prover conteúdos ao formato representativo, ou o objetivo primordial de uma eleição, que é eleger representantes.

Dentro da discussão sobre votos válidos e alheamento eleitoral, todo voto válido é a manifestação de uma escolha, e todo alheamento eleitoral é a ausência desta escolha. Enquanto o montante de votos válidos permite que a política siga adiante, 0 alheamento eleitoral não apresenta uma resposta. 0 voto válido atribui conteúdo à decisão, o alheamento eleitoral potencialmente paralisa o processo.

Pela idéia de alheamento percebe-se uma postura de se esquivar de determinada situação pela opção de auto-exclusão. 0 estado mental que leva a

dividido entre uma urna e um fuzil.

AlHeAmento ELEITORAL: ReFLEXÕES SOBRE O SIGNIFICADO DE VOTOS... 
este comportamento não está explícito na ação, mas o alheamento eleitoral é, antes de tudo, o registro de um vácuo na escolha popular ${ }^{8}$.

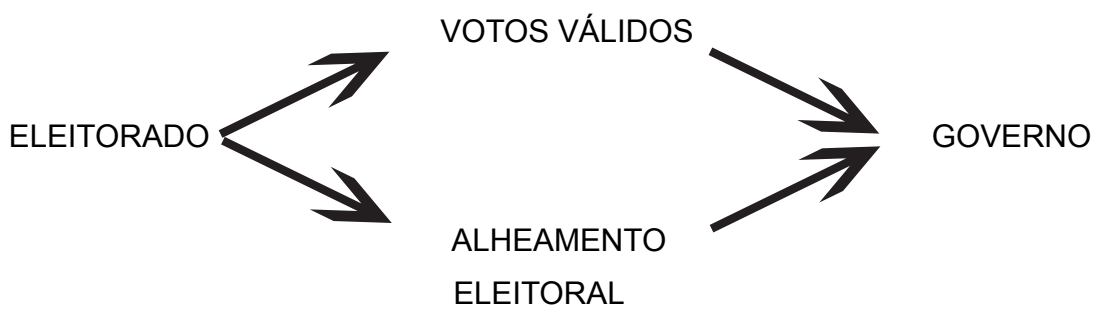

Para isolar este conceito de outros termos com os quais ele possui semelhança etimológica, é importante deixar claro que o termo "alheamento" não significa o mesmo que "alienação", apesar de ambos advirem do vocábulo latino alienare. Alheamento eleitoral não remete, imediatamente, a uma ausência de consciência/desconexão mental com a realidade, poiséum comportamento. Assim, o termo não está imbuído das complexidades que caracterizam a subjetividade da alienação.

É igualmente importante diferenciar "alheamento eleitoral" de "alheamento político", pois a política é ampla e não se restringe às eleições. A decisão por não escolher um candidato nas eleições não necessariamente corresponde a uma ausência de engajamento político, pois o alheamento eleitoral, se motivado por protesto contra o sistema (bastante comum entre os anarquistas), contrapõe-se diretamente à idéia de alheamento político.

Uma última questão a ser esclarecida é a diferença entre alheamento eleitoral e ausência de participação política ou ainda não-participação eleitoral. 0 voto em branco e o voto nulo são englobados pelo conceito de alheamento eleitoral e ao mesmo tempo não significam uma não-participação, pois ambos se efetivam por meio do comparecimento às urnas. Desta forma, a ausência de

\footnotetext{
${ }^{8} 0$ alheamento eleitoral pode também ser conseqüência de um erro mecânico (falta de familiaridade com a urna eletrônica, cédula confusa e ambígua, entre outras falhas procedimentais) ou ainda incapacidade de acesso ao local de votação. Estas possibilidades, porém, não representam escolhas (manifestação da liberdade), e sim restrições estruturais. Além disso, uma das constatações após a introdução das urnas eletrônicas no Brasil foi a queda considerável de votos inválidos, o que indicaria uma maior operacionalidade dessas urnas principalmente para populações menos esclarecidas.
} 
decisão não equivale à ausência de participação - a não-participação em eleições implica somente em um dos elementos que constituem 0 alheamento eleitoral (abstenção).

Como por trás de toda ação social existe alguma intenção, é importante observar primeiro os comportamentos eleitorais alheios (votar em branco, anular 0 voto ou se abster) vinculados a comportamentos políticos (apatia e protesto), e depois, suas possíveis motivações (alienação, satisfação, ou insatisfação política), que são a dimensão subjetiva do processo.

0 voto em branco, em geral, não expressa preferência, e também não corresponde a um voto "vazio". 0 cidadão deposita uma cédula inalterada na urna, ou aperta o botão "branco" na urna eletrônica, e o único registro é a presença de sua pessoa no dia de eleição, mas não de sua escolha. Corresponde, no mínimo, a um comparecimento às urnas, mas, como o voto nulo, o voto em branco faz parte da esfera de votos estéreis (COSTA PORTO, 1999).

Assim como o voto em branco, o voto nulo não apresenta uma escolha. "A doutrina costuma distinguir, dentre os eleitores que votam nulo, aqueles que 0 fazem deliberadamente e os que o fazem por ignorância ou erro, sem consciência da impropriedade de sua escolha" (COSTA PORTO, 1999). No caso de anulação deliberada de votos, associa-se um comportamento de protesto político ao alheamento eleitoral.

A abstenção, por último, caracteriza-se pelo não comparecimento do eleitor às urnas em dias de eleição. Ela é a manifestação mais clara de apatia ou de protesto eleitoral.

\section{O QUE O ALHEAMENTO ELEITORAL TRADUZ?}

As razões pelas quais o indivíduo não escolhe seus representantes podem ser inúmeras. Não existe consenso na literatura especializada sobre as causas deste tipo de comportamento, mas pode-se dizer que o alheamento eleitoral é fruto de estados de consciência e de comportamentos políticos gerais, que se manifestam de forma específica em eleições.

\section{AlienaÇão}

Geralmente utiliza-se o termo "alienação política" para se dirigir ao alheamento eleitoral, mas a alienação política é um estado de consciência muito 
mais amplo do que o comportamento específico em eleições. Ela refere-se a uma desconexão do indivíduo em relação ao meio em que está inserido, ou seja, é uma espécie de lacuna de consciência, uma distância mental dos significados das ações individuais no meio coletivo.

A noção de responsabilidade e compromisso social não existe no sujeito alienado, pois este não reflete sobre suas ações, que são automáticas, sem questionar o mundo ao redor ${ }^{9}$. Desta forma, o indivíduo alienado da esfera políticoeleitoral não tem contato subjetivo com o ambiente em questão, ou seja, pode não haver distância física, mas existe grande distância psicológica (alienação dos significados dos processos). Um indivíduo pode estar alienado tanto de si mesmo quanto do ambiente em que se insere (muitas vezes os dois tipos de alienação estão sobrepostos). Pode-se categorizar quatro tipos de cenários que desencadeiam o sentimento de alienação (BOTTOMORE, 1998):

1) Os indivíduos se encontram alienados em relação aos resultados de sua própria atividade (e em relação à atividade em si como processo). Isto se encaixa tanto no voto volátil ou "inconsciente" quanto no alheamento eleitoral sem propósito político.

2) Os indivíduos se encontram alienados em relação ao meio em que vivem (aplica-se especificamente ao cenário da política e ao clima de eleições) e/ou

3) Os indivíduos se encontram alienados em relação a outros seres humanos. Este ponto está ligado à ausência de identificação com os representados semelhantes, à ausência de conexão com a opinião dos outros, à ausência de debates entre cidadãos (incentivado pelo sistema de voto como algo secreto e privado), e à distância que leva à desconexão entre representante e representado/ candidato e eleitor .

4) Os indivíduos se encontram alienados em relação a si mesmos, em relação às suas próprias possibilidades humanas. Este ponto é mais existencial e ligado à condição humana no mundo.

\footnotetext{
${ }^{9}$ Comportamento automático, oposto à consciência questionadora (sujeito em movimento sem refletir sobre suas ações), é amplamente descrito por Marx em sua análise sobre o capitalismo. Ver Raniere (2001).
} 


\section{SATisfação}

A satisfação e a insatisfação política diferenciam-se da alienação pois são resultados de uma reflexão sobre a política (ou seja, cidadãos satisfeitos ou insatisfeitos são racionais ${ }^{10}$ e não alienados). Satisfação pode ser definida como prazer, aceitação, contentamento; pois o mundo político-social corresponde ao que se deseja. 0 indivíduo satisfeito sacia-se com a realidade. Neste caso, o comportamento alheio é uma opção "consciente e racional", na qual a pessoa não se dá ao trabalho de escolher um representante porque a realidade política está boa. Quando o alheamento eleitoral é resultado de satisfação, não existe um caráter de "conflito velado" nem de "asfixia". Seria uma satisfação tão grande com a esfera pública, que o indivíduo sente que pode usufruir em paz de sua esfera privada.

\section{INSATISFAÇÃ̃O}

A insatisfação é uma forma de inadequação como o meio político. 0 sujeito não se sente parte integrante da política e se incomoda com isso. Geralmente sente-se incapaz na esfera pública, ou dividido entre esfera pública e esfera privada, em um estilo que se assemelha ao sujeito social anômico de Durkheim (DURKHEIM, 2000), ou ao homem democrático descrito por Alexis de Tocqueville (TOCQUEVILLE, 1987).

\section{Apatia}

A apatia, diferente da alienação, da satisfação e da insatisfação, é um comportamento. Ela expressa a inércia do indivíduo, sua baixa receptividade aos estímulos políticos, tendendo a estabelecer uma ausência de autonomia. A pessoa simplesmente não reage. A maior característica do indivíduo apático é que ele não efetiva suas próprias intenções por meio de atividades - no máximo, acompanha os acontecimentos como um espectador, destacado da dinâmica social, quando não ignora tudo por completo. A pessoa apática é indolente ou indiferente, e seu comportamento possui causas que podem vir de diferentes estados de consciência ou sentimentos:

\footnotetext{
${ }^{10}$ Esta idéia de cidadão racional permeia todas as teorias do liberalismo clássico e contemporâneo, contraposta aos marxistas e elitistas em geral, que trabalham, cada um ao seu modo, com a idéia dos "governados alienados".
} 
a) Sentimento de incapacidade individual, que pode variar entre insegurança pessoal até limitações estruturais (quando a pessoa não é capaz de decodificar a política - desde os programas de governo e discursos dos candidatos até o voto em urna de lona ou eletrônica). É como se a política intimidasse o cidadão comum ${ }^{11}$.

b) Sentimento de impotência social perante as circunstâncias (neste caso, a apatia não é um sinônimo de falta de consciência). Mesmo que discorde de algo, o indivíduo não crê que tenha poder suficiente para tomar iniciativas de mudança, pois o sistema não permite ações de impacto por parte do cidadão comum isolado. 0 indivíduo se percebe estruturalmente destacado da esfera política. De acordo com esta postura, um único voto não é objetivamente capaz de fazer qualquer diferença. A impotência social está ligada à descrença, geralmente oriunda da desqualificação das instituições e dos atores políticos.

c) Sentimento de indiferença em relação ao processo político-eleitoral, considerado de pouca importância em comparação a outras dimensões da vida privada. Os sentimentos do indivíduo em relação à política são de negligência voluntária, onde não se busca informação política e tampouco se age politicamente.

\section{Protesto}

0 protesto é uma manifestação de oposição, uma contestação da ordem vigente. 0 voto de protesto (válido ou nulo) demonstra clara insatisfação com 0 sistema, e pode ser relacionado aos seguintes pontos:

a) Rejeição ao Estado e à comunidade política nacional, pois acredita-se em uma ordem política onde não existem essas instituições (é o caso dos anarquistas e de algumas formas de comunismo);

b) Rejeição ao sistema representativo em geral efetivado pelas eleições, ou seja, protesta-se em relação aos arranjos institucionais da democracia representativa. Quando esta é a origem do protesto, geralmente o indivíduo se abstém da votação, intencionalmente deixando de legitimar as regras do sistema, ou então anula seu voto.

\footnotetext{
${ }^{11}$ Eliasoph (1998) descreve o caráter intimidador da esfera política e como as pessoas muitas vezes participam em nível cívico e comunitário, mas recusam-se a interferir em política de nível macro.
} 
c) Rejeição ao sistemapolítico específico, considerado pouco representativo, pouco democrático ou mesmo injusto. Este pode ser o caso do voto válido em micropartidos, ou da anulação do voto por minorias extremistas ambos em protesto contra regras que obstruem o acesso amplo à esfera política.

d) Rejeição à conduta dos representantes dos governos, ao exercício considerado deturpado ou amoral da política. Seria a falta de credibilidade dos governos em relação aos ideais e valores da população.

0 alheamento eleitoral como protesto advém somente da insatisfação. Enquanto a apatia corresponde a letargia frente ao meio coletivo, o protesto corresponde à contestação - e ambos podem se expressar por rejeição silenciosa pela via eleitoral ${ }^{12}$.

\section{INTERPRETAÇÃO DO ALHEAMENTO ELEITORAL}

Algumas tentativas de explicar o alheamento eleitoral podem ser resumidas em duas perguntas:

1) 0 alheamento eleitoral é uma forma de questionamento político?

2) Independente de ser uma forma de questionamento, o alheamento eleitoral é um agente capaz de deslegitimação?

Vários autores responderiam estas perguntas. Dentre eles, existem os que enfocam a estabilidade do sistema como o objetivo máximo, ou seja, como elemento necessário e suficiente para a democracia representativa. Mas também existem aqueles que priorizam a qualificação do eleitorado como o maior indicador democrático, ou seja, além de estabilidade (elemento necessário), é preciso que os cidadãos se identifiquem com a política (elemento suficiente).

Entre os autores que priorizam a estabilidade, Giovanni Sartori diria que nas democracias contemporâneas, denominadas "democracias verticais", os princípios e mecanismos não precisam estar "ao alcance intelectual do cidadão comum" (SARTORI, 1996, p. 33).

\footnotetext{
${ }^{12}$ Esta idéia de insatisfação e protesto pelo alheamento eleitoral é comum em regimes autoritários com sistemas de voto obrigatório, como foi o caso de muitos centros urbanos no Brasil antes de 1974, quando o MDB ainda não tinha credibilidade de oposição, e em demais países da América Latina submetidos a regimes autoritários.
} 
Sartori afirma que "Como forma política, a democracia tem de reduzir a vontade múltipla de milhões, dezenas e até centenas de milhões de pessoas dispersas em uma única autoridade; e isso significa que as condições segundo as quais uma sociedade democrática deve atuar são apenas uma aproximação remota das condições ótimas encontradas em grupos primários e comunidades pequenas e integradas. Entre uma democracia cara a cara e uma democracia em larga escala existe um abismo imenso. (...) Portanto, se ainda temos uma democracia no sentido político, não podemos esperar da desajeitada democracia de larga escala o que podemos esperar das microdemocracias." (SARTORI, 1996, p 32).

Com esta afirmação, Sartori defende que a simples manifestação quantitativa não é suficiente para desqualificar os procedimentos e a legalidade consolidada. A avaliação da coerência ou incoerência interna das opiniões expressas eleitoralmente, em agregados de votos válidos ou em alheamento eleitoral, tornase um problema complicado, e não há como fundamentar a legitimidade de um sistema político em objetos velados.

Sartori acredita que a apatia existe justamente para demonstrar que nem todos estão envolvidos, por incapacidade, incompetência ou desinteresse em manifestar uma escolha de representante. Portanto, o fato de alguns segmentos dissolvidos na multidão não se manifestarem apenas contribui para a qualificação da democracia como um sistema tolerante.

Sartori, em inspiração profundamente schumpeteriana, explicita 0 desinteresse dos indivíduos nas democracias representativas: "0 cidadão típico cai para um nível mais baixo de atividade mental assim que adentra o campo político. Argumenta e analisa de uma forma que reconheceria imediatamente como infantil na esfera de seus interesses reais. Torna-se primitivo outra vez. Seu pensamento torna-se associativo e afetivo..." (SARTORI, 1996, p.151).

Sartori afirma que relações políticas autênticas e efetivas só são possíveis em microdemocracias ou em grupos de elite, pois " Poucos fazem melhor, e contam mais, do que muitos passivos, inertes, apáticos e não-participantes" (SARTORI, 1996, p. 160). Além disso, se aqueles que protestam (chamados de extremistas) não forem maioria da população, eles são funcionais por contestar utilmente 0 excesso de inércia do cidadão passivo, equilibrando o conjunto e desempenhando um papel positivo para a estabilidade (mesmo que esta não seja a intenção dos radicais isolados). 
Assim parece claro que o alheamento eleitoral interfere pouco, ou quase nada, na legitimidade das democracias contemporâneas. A dimensão numérica das eleições é lateral, já que a própria participação é secundária, (pois a percepção política do cidadão é volátil e confusa). 0 que interessa para a legitimidade do sistema são os valores das elites dirigentes. A participação é apenas um apoio para a democracia concorrencial. Assim, ainda que a esfera do alheamento eleitoral seja grande em termos quantitativos, não possui poder suficiente para afetar a estabilidade da democracia ou deslegitimar o poder.

Seymour Lipset interpreta o comportamento dos eleitores em um sentido semelhante. 0 autor tenta demonstrar o funcionamento da democracia como uma articulação entre conflito e consenso, que permite a expressão das diferenças mediante consenso quanto às regras do jogo (LIPSET, 1960).

Nesta afirmação, em um primeiro momento pode-se achar que, sendo o voto uma manifestação de consonância com as regras do jogo, o alheamento seria uma demonstração de dissenso. Porém, para Lipset, alheamento eleitoral (e ele fala especificamente de abstenções, e não de votos em branco ou votos nulos) não se encaixa em uma forma de questionamento. Ele seria apenas uma demonstração ainda mais intensa da aceitação da população em relação aos rumos da política e ao sistema, de forma tão absoluta que o eleitor sequer sente necessidade de se fazer presente. Para Lipset, quem cala consente, ou seja, os indícios de fragilização da legitimidade não estão no silêncio eleitoral, mas sim em votos oposicionistas, extremistas, ou nas queixas e manifestações populares (LIPSET, 1960, p. 12).

Isto fica claro quando ele afirma que "a crença de que um alto grau de participação é sempre benéfico para a democracia não é válida. Um crescimento no nível de participação pode refletir um declínio da coesão social e indicar a falência do processo democrático; enquanto uma democracia estável pode se sustentar na crença geral de que os resultados de uma eleição não farão muita diferença em uma sociedade" (LIPSET, 1960, p.14).

Pelas leituras que Lipset faz da política, o conflito e a mudança suscitam muito mais interesse nas pessoas do que a conservação e a manutenção de determinado sistema. Crises e mudanças possuem um apelo público maior. Assim, a ausência de interesse, inclusive por alheamento eleitoral, seria um indício de estabilidade da democracia representativa.

0 problema para Lipset só começa quando os conflitos inerentes (ameaça potencial constante) acirram-se e efetivam-se para além da prática eleitoral, a 
ponto de romper com as estruturas anteriores. Neste sentido, Lipset considera saudável para a democracia que os indivíduos não sejam muito comprometidos politicamente. Ao que tudo indica, a ausência de conflito legitima qualquer poder, contribuindo para a ordem pública (1960, p 32).

Segundo Huntington, este fenômeno estaria, também, ligado à rebeldia das novas gerações e ao fato da esfera privada desmotivar os interesses pela esfera pública, levando a uma mentalidade "privatista" e uma alienação voluntária do processo político. Este comportamento foi ainda reforçado por instabilidades econômicas - 0 impacto de uma economia em crise reverbera no interesse político (1975, p. 75).

As ameaças à legitimidade não estariam, portanto, na passividade do alheamento eleitoral. Muito pelo contrário, estariam na atividade política extraeleitoral, no aumento cada vez maior de críticas e demandas sobre o governo e 0 Estado, principalmente durante os mandatos.

No fundo, Huntington se preocupa com o problema da "governabilidade", e 0 alheamento eleitoral não é um obstáculo para isso. A participação nãoinstitucional (ou seja, a expressão política além dos votos) pode ser um forte elemento deslegitimador (1975, p. 84). Assim, são os protestos políticos de grupos organizados, e não alheamento eleitoral (que é o resultado de ações individuais isoladas em eleições), que fragilizam a democracia representativa.

Huntington, como Lipset, também partilha da idéia de que o povo definitivamentesefazmaispresenteem momentosdecrise, ao definir "desobediência civil" como uma alegação de se estar moralmente certo ao desobedecer uma lei que está moralmente errada. Uma atitude que desafia a autoridade do governo está relacionada ao protesto extra-eleitoral e à insatisfação racional direcionada - jamais à apatia ou à alienação. 0 alheamento eleitoral, isoladamente, pode ter impacto sobre a legitimidade do governo (principalmente se os índices de nãodecisão forem muito altos), mas não rompe com as estruturas do Estado, nem do regime, nem da comunidade política (HUNTINGTON, 1975, p. 85).

Para Almond e Verba, em um outro tipo de visa, diversas tensões mentais se criam ao redor dos eleitores (1966, p. 13). Para eles, existem três tipos de orientação política:

1) orientação cognitiva: conhecimento ou crença do indivíduo em relação ao sistema político e seus papéis. 
2) orientação afetiva: sentimentos do indivíduo em relação ao sistema político e seus papéis, cargos e desempenho.

3) orientação avaliativa: julgamentos e opiniões que os indivíduos dirigem aos objetos políticos.

Almond e Verba consideram o sistema de democracia representativa a mais evoluída das formas de governo. Mesmo assim, admitem tratar-se de um sistema que pode existir precariamente. As relações de congruência e incongruência entre a estrutura política e a cultura - entre o sistema político e eleitorado - é apresentada no diagrama transposto abaixo:

\begin{tabular}{lcccr} 
& Adesão & Apatia & Alienação \\
\cline { 1 - 2 } Orientação cognitiva & + & + & + \\
Orientação afetiva & + & 0 & - \\
Orientação avaliativa & + & 0 & -
\end{tabular}

0 símbolo para uma congruência forte, altos índices de consciência ou sentimentos positivos em relação ao sistema é (+). Para uma congruência fraca, que corresponde a indiferença, é (0); e para uma incongruência, ligada a sentimentos negativos e rejeição, é (-).

Almond e Verba propõem que esta escala seja vista como uma expressão de estabilidade/instabilidade. Ao deslocar a atenção para a esquerda, o regime é caracterizado por uma situação de adesão, ou seja, pela combinação harmoniosa de atitudes e instituições. Se a atenção se volta para a coluna direita, a relação é de alienaçãa $0^{13}$.

Almond e Verba afirmam que a estabilidade política está participação ideal, composta por conscientização e ação moderada. Por ação moderada entende-se disponibilidade nos momentos requisitados institucionalmente para participar na forma de voto, e não mais do que isto. Os valores compartilhados por este tipo de sociedade ajudariam os indivíduos a não "extrapolar" sua ação, ou seja, não interferir no mandato.

\footnotetext{
${ }^{13}$ Por "alienação" os autores entendem uma rejeição às estruturas políticas, e isso é descrito neste trabalho como "insatisfação". A definição de alienação é ausência de consciência. "Rejeição" necessariamente implica em algum tipo de questionamento, o que torna inadequada a escolha da palavra "alienação" pelos autores.
} 
Assim, sendo a legitimidade uma forma de reconhecimento, Almond e Verba afirmam que se a esfera dos votos válidos permanece, o alheamento eleitoral não a deslegitima, pois a omissão de uns não pode anular a escolha de outros. Se a consciência política não se materializa em votos, esta situação não é democraticamente ideal, mas tampouco é deslegitimadora.

A pedra fundamental da legitimidade democrática encontra-se, portanto, na mistura de padrões comportamentais na população. 0 alheamento eleitoral não é elemento de conflito no interior da estrutura eleitoral. 0 que poderia abalar a legitimidade de um governo para Almond e Verba seria um desequilíbrio na relação entre poder e accountability, ou seja, a base da legitimidade é uma "ética da responsabilidade". 0 que fere a legitimidade de um governo é a falta de credibilidade e sensibilidade de líderes, a má organização e precariedade dos sistemas de responsabilidade e confiança, independente da população perceber isso ou não.

0 pensamento dos autores se resume na seguinte argumentação: "0 cidadão democrático é requisitado para concretizar objetivos contraditórios: deve ser ativo ao mesmo tempo ser passivo; envolvido, mas não muito; e exercer influência, mas não deferência" (ALMOND E VERBA, 1966, p. 343-4). Assim, para satisfazer um ideal democrático o eleitor deve ser ativo, informado, racional, influente. Para estar de acordo com os limites que a realidade impõe, porém, ele deve ser passivo, pouco informado e voltado para sua esfera privada. A democracia seria um fracasso se o comportamento dos atores correspondesse em gênero, número e grau às idealizações. Afinal de contas, como os próprios autores argumentam, "pode simplesmente não valer a pena ser um bom cidadão" (ALMOND E VERBA, 1966, p. 340), já que a maioria dos interesses do cidadão comum (que não é o cidadão ideal) não são políticos. 0 cidadão comum não se identifica e nem acompanha a complexidade dos eventos políticos (a assimetria de informações é muito grande e não vale a pena tentar diminuí-la) e além disso, ele possui outras demandas individuais, mais importantes do que questões públicas.

A melhor forma de se concretizar uma democracia representativa seria, portanto, que existissem altos níveis de percepção e baixos níveis de ação. Dentro desta perspectiva, eleições são a manifestação máxima de uma atividade mental e uma passividade comportamental na política democrática.

Dentre os autores que priorizam a qualificação do eleitorado, Almond e Verba podem ser considerados fronteiriços. Mas existem argumentos que julgam 
a auto-exclusão em escolhas eleitorais algo negativo para a democracia. Autores como Pateman e MacPherson não consideram a apatia indicativo de satisfação com o sistema. Assim, tais interpretações priorizam a atuação política constante, diferente do reducionismo eleitoral, que afasta representado de representante, cria elites políticas, e conseqüentemente, produz sentimentos de incompetência nos governados .

Autores como Lipset, Sartori, Huntington e Almond e Verba enfatizam que a estabilidade das democracias representativas está entre outros aspectos, em aceitar um cenário político de desigualdade estrutural. Os outros autores a serem abordados daqui para frente criticam este tipo de pensamento, ao enfatizarem a qualidade da dimensão participativa, que inclui acompanhamento de mandatos e interferência política cotidiana. 0 alheamento eleitoral seria, para esses autores, quase uma resignação.

Segundo os críticos da democracia competitiva, o fato de se reduzir a democracia representativa a uma competição entre elites e assumir que este é o melhor meio de incluir a participação das massas é uma postura que destrói os fundamentos de igualdade e participação da democracia. Não se trata de eliminar a representação, mas de diminuir as distâncias espaciais e psicológicas entre representante e representado. Na realidade, a base da democracia estaria na identidade, algo perfeitamente compatível com representação política.

Macpherson critica a equivalência da democracia representativa às relações de mercado, resgatando princípios éticos das teorias clássicas de democracia, ligadas à participação consciente, que foram abandonadas pela democracia de equilîbrio por serem consideradas inexeqüíveis (1978, p. 91). Segundo ele, a "democracia pré-liberal", postulada por Rousseau ${ }^{14}$, é onde a vontade geral do povo é o elemento mais importante, e a estrutura social é de profunda igualdade material ${ }^{15}$.

Já a democracia liberal concebida por Jeremy Bentham e James Mill pressupõe uma divisão de classes pré-exisitente. Ela é o que Macpherson denomina "democracia protetora" e baseia-se na salvaguarda dos indivíduos perante o poder

\footnotetext{
${ }^{14}$ Esta leitura é historicamente equivocada, pois o liberalismo clássico existe antes de Rousseau nascer, então seu pensamento não pode ser "pré-liberal".

${ }^{15}$ Seja como for, a igualdade material em Rousseau tem um elemento peculiar de frugalidade absoluta, sem propriedade e sem "necessidades artificiais", onde cada um tem apenas 0 estritamente necessário para a sobrevivência física.
} 
de opressão de um estado centralizador ${ }^{16}$. A democracia liberal edifica-se sobre uma diferença de classes, usufruindo da ruptura na ordem de dominação vertical entre soberano e súditos para incluir um novo segmento social na esfera das decisões políticas (burguesia). As bases da participação foram ampliadas, mas não para a sociedade como um todo - apenas para as novas elites.

Segundo Macpherson (1978, p. 98), as teorias contemporâneas de democracia resgatam a exclusão das grandes massas e renegam o princípio de participação qualitativa igualitária. Ele diferencia mecanismo democrático de bumanismo democrático, e afirma que os autores que seguem a linha de Schumpeter focalizam o primeiro e desprezam o segundo. Esta seria a "Democracia de Equilibrio", adotada pelos autores da estabilidade suficiente.

Macpherson ilustra a relação entre representante e representado com uma analogia ao mercado (1978, p. 107):

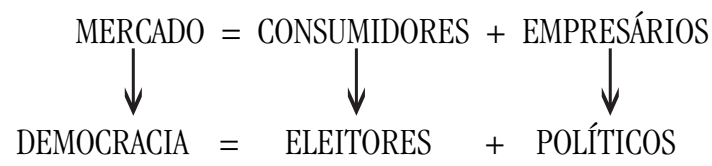

Dentro desta idéia, se alguns membros da sociedade se recusam a consumir (alheamento eleitoral), isso não quer dizer que o mercado não continue sobrevivendo. As quedas no consumo desencadeiam crises, mas eventualmente 0 mercado se recupera.

Macpherson critica a assepsia deste pensamento, por reduzir a esfera política a mecanismos de rodízio das elites no poder. Já a explicação da realidade e as constatações do funcionamento do processo e de suas consequiências confundem a explicação com a justificativa. Macpherson afirma que este tipo de relação elimina os valores igualitários da democracia no meio do caminho. Em contraposição ao homem racional e interessado pela esfera pública da democracia pré-liberal (ou o que Schumpeter denominou democracia clássica), este modelo assume que a população decai para um grau inferior de racionalidade ao lidar com política, pelo fato desta não fazer parte de seu cotidiano, e considera isto desejável. Este tipo de argumento sugere um incentivo social à tutela de Estado, à satisfação por apatia política e voto válido, ou no máximo, à insatisfação política limitada a protestar por alheamento eleitoral.

${ }^{16}$ Isto significa, especificamente, abuso do poder de taxação. 
Contraposta à visão descritiva da Democracia de Equilíbrio, Macpherson propõe uma democracia participativa, na qual a representação permanece, mas o eleitorado é qualificado, e as atenções do sistema centram-se na participação (MACPHERSON, 1978, p. 107). Os mecanismos para qualificar o voto seriam diminuição das desigualdades materiais, sofisticação do eleitorado e fomento de confiança nos responsáveis pela esfera pública. Em síntese, a solução estaria na diminuição de todas as distâncias.

Carole Pateman afirma que as teorias contemporâneas sobre democracia ergueram-se sobre bases distorcidas ao dizer que democracia participativa é impossível em largas escalas populacionais. Pateman, alternativamente, propõe que democracia é participação, voto e discussão, sempre com uma referência nos ideais de igualdade e autonomia (PATEMAN, 1992, p. 9). Mesmo que eles não correspondam à realidade representativa atual, podem servir de norte.

0 alheamento eleitoral seria indicativo de que algo está desconectado entre a realidade política e os ideais democráticos, ou seja, indica insatisfação e/ou sentimento de incompetência. E se a realidade política é uma construção social, ela pode ser mudada por novos valores e práticas.

Segundo Pateman, as teorias da estabilidade suficiente são descritivas e concentram-se no governo equilibrado de minoria ativa. A estabilidade do sistema necessita de uma cidadania homogênea, e se ela residir em uma maioria silenciosa, tanto melhor. Além disso, Pateman ressalta a deturpação do conteúdo democrático do sistema pelo enfoque na competição. Esta seria uma visão reducionista de participação, assim como é reducionista resumir igualdade política ao sufrágio universal, ignorando as distâncias entre representante e representado.

Combatendo o argumento de Sartori de que "as pessoas não aprendem a votar votando" (SARTORI, 1996), Pateman acredita que o espírito público só pode vir da prática, do aprendizado na participação. Se o voto é uma participação privada e secreta, o espírito público fica desconectado da ação política, o que seria outro contra-senso para a democracia.

Os motivos da apatia estariam ligados à ausência de responsabilidade concreta do indivíduo. Os arranjos institucionais da democracia representativa contemporânea oferecem participação reduzida, onde 0 indivíduo não tem controle sobre as "decisões coletivizadas", e por isso, Pateman considera que 0 eleitor mediano não percebe que faz parte de um agregado (PATEMAN, 1992, p. 21). Se a pessoa sabe que sua participação não terá efeito objetivo nas decisões 
políticas, por estar diluída em milhões e por ser indireta, participar é um custo. No entanto, se os ajustes institucionais deslocarem o foco para a participação qualitativa, onde a decisão do indivíduo tem impacto concreto sobre a realidade (descentralização de decisões, ou no mínimo, de iniciativas), o efeito psicológico é outro, e talvez a apatia não seja mais tão vantajosa. A participação "alienada" pode se tornar uma participação democrática autêntica, se 0 cidadão comum começa a tomar consciência do que é público, inserindo-se em questões coletivas. A chave está na mudança de mentalidade pela identificação com a esfera pública.

Segundo Pateman, quem se sente parte de uma coletividade não se alheia nem política nem eleitoralmente. É neste ponto que se qualifica um eleitorado. As mentalidades dependem da realidade que rodeia a população, dos tipos de estímulo, de educação pública, que são todas variáveis manipuláveis. Se os defensores da estabilidade suficiente afirmam que o indivíduo é apático porque é auto-centrado e confere maior importância à esfera privada (PATEMAN, 1992, p. 26), não se trata de natureza humana imutável, e sim da realidade socialmente construída.

Pode-se elevar a qualidade do eleitorado com uma engenharia nos estímulos externos - implementar novos arranjos institucionais com o intuito de inserir a política no ambiente local de cada cidadão, inserindo uma consciência de controle real. "É claro que as decisões tomadas, por exemplo, no local de trabalho e na Câmara dos Deputados não são exatamente as mesmas, mas pode-se concordar com Schumpeter e seus seguidores pelo menos a este respeito: é de se duvidar que o cidadão comum chegue algum dia a se interessar por todas as decisões que são tomadas em nível nacional da mesma forma que se interessaria por aquelas que estão mais próximas dele" (PATEMAN, 1992, p.46). Mas se as decisões não são de mesmo alcance, têm o mesmo princípio de decisão direta, de sentir na própria experiência a responsabilidade de coletivizar uma diretriz política.

Pierre Bourdieu (1984, p. 397) afirma que a abstenção eleitoral é uma das condições para o funcionamento do sistema, e não uma mera externalidade. Isso quer dizer que a ausência de resposta, voto e/ou opinião não enfraquece a legitimidade do sistema - pelo contrário, reforça a legitimidade da minoria competente que conduz o processo (realização de eleições + votos válidos). A base da legitimidade nesta visão é que, independente do indivíduo possuir ou não as capacidades de fornecer respostas, votos e leituras conscientes da realidade, o sistema assume que ele possui estas capacidades dadas, e se o indivíduo não vota, 
isso é apenas uma opção de cidadão livre. Trata-se do que Bourdieu denomina "produção ideológica" (1984, p. 399).

Bourdieu, ao contrário, afirma que as pessoas geralmente não se abstêm em questões com as quais têm familiaridade. Tudo depende do grau de contato que o indivíduo possui com o meio social (e da qualidade deste contato). Quanto mais abstrata a questão, mais longínquo torna-se o contato, e mais inconsistentes ficam 0 interesse e a capacidade de interferência do cidadão comum. À medida que questões se afastam da esfera privada e se aproximam da esfera pública, as pessoas tendem a não ter opinião formada e muitas vezes sequer sabem do que se trata 0 assunto.

Neste sentido, a diferença entre um regime aristocrático e um regime democrático nos moldes contemporâneos é a auto-exclusão que caracteriza este último. A rigor, um sistema político formado por minoria governante e sufrágio universal se caracteriza por permanente tensão, pois as massas seriam donas de um poder latente real, capaz de alterar as estruturas sociais. É por isso que, nos argumentos de Bourdieu, a apatia não apenas legitima o sistema, mas é também funcional para sua sustentação (1984, p. 414).

Por conseqüência da hierarquia entre classes, a capacidade de decodificar a complexidade do universo político parece restrita ao "topo da pirâmide" social. Objetivamente, o interesse e a indiferença dependem da capacidade de compreensão do sistema e de relacionar a dinâmica social com a realidade individual, inclusive para exercitar o poder político (por voto, influência, pressão, cobrança). Assim, a indiferença pode ser uma manifestação de impotência, diametralmente oposta ao interesse, que surge da possibilidade de exercer poder concretamente, e em democracias, é onde reside a responsabilidade social (BOURDIEU, 1984, p. 422)

Com enfoque em elementos qualitativos, Bourdieu afirma que a opinião política confere qualidade às ações - ela contém uma pretensão de se tornar realidade. Se o discurso político está para a competência assim como o silêncio está para a incompetência, o alheamento eleitoral não é uma forma de poder político, pois não promove rupturas e não tem discurso claro e direcionado de transformação, e portanto, mantém a ordem (1984, p. 437). Em democracias genuínas, a capacidade de interferência no processo é ativa, e não reativa ou passiva. Se o indivíduo não tem opinião (e se tem, a expressa por meio do silêncio), ele não tem poder para deslegitimar, e a legitimidade mantém-se institucionalmente, reduzindo-se à legitimidade geral. 
Essas idéias criticam tanto a democracia representativa quanto as teorias de estabilidade suficiente, afirmando que o sistema atual provoca 0 afastamento dos cidadãos. A falta de estímulo em participar, por causa das largas escalas, da incapacidade de interferência real, e da conseqüente falta de interesse e falta de autoconfiança seriam os principais motivos da apatia ou do protesto silencioso.

No que se refere ao alheamento eleitoral, o comportamento de autoexclusão nas eleições só serve para reforçar o caráter pouco democrático, porque pouco participativo, das democracias representativas. Não seria um elemento funcional para a manutenção do equilíbrio da sociedade como um todo, e sim para a manutenção de um cenário desigual pela natureza de princípios de competitividade, e não de igualdade.

\section{Conclusão}

A conclusão que se chega é, enfim, que o alheamento eleitoral pode ser, realmente, uma forma de questionamento político (pois pode demonstrar insatisfação e protesto). Mas ele não consegue, por si só, qualificar-se como forma de deslegitimação, pois não é um poder desestruturador da democracia representativa (a não ser que exista associado a outras formas de questionamento político).

As duas correntes interpretativas apresentadas concordam quanto à descrição da realidade da democracia representativa (apesar de existirem profundas divergências quanto aos significados do alheamento eleitoral). Mas principalmente, concordam quanto à relação entre alheamento eleitoral e legitimidade. Independente das motivações atribuídas ao alheamento eleitoral, todos os autores concordam que ele não é fator de deslegitimação, embora seja capaz, quanto maior for seu grau, de fragilizar bastante a legitimidade de um governo específico. Isso pode acontecer em especial em contextos de turbulência social, mas de forma isolada, não seria um instrumento suficiente para abalar a estrutura democrático-representativa como um todo, nem a comunidade política, nem o Estado.

A teoria política contemporânea ainda tem muito a descobrir sobre a atual distância física e psicológica entre representantes e representados ${ }^{17}$. ${ }^{17}$ A visão de Schumpeter (1942) de eleitorados ampliados como multidões psicológicas pode
esclarecer esta idéia de distância. 
Joseph Schumpeter, mesmo postulando conclusões muito cruas sobre o que é democracia, avaliou que, em política, a distância distorce as visões de mundo, e que a competência política está na experiência de decidir. Em democracias representativas, a posição que resta ao cidadão comum é, estruturalmente, distante das decisões públicas reais. Se o cidadão comum é apenas atingido por decisões coletivizadas, e as únicas decisões políticas que tomam são votos periódicos que delegam poder e elegem outros, o alheamento eleitoral não é uma forma de deslegitimação estrutural, mesmo se a intenção for esta.

0 alheamento eleitoral não deslegitima o sistema, em primeiro lugar, porque a deslegitimação é uma atividade que pressupõe articulação de um grupo social, e não se efetiva no silêncio desagregado do alheamento eleitoral. Em segundo lugar, pelo fato do alheamento eleitoral se manifestar nos âmbitos oficiais do Estado, isoladamente ele não tem poder, a não ser que a intenção seja apenas simbólica ${ }^{18}$.

0 alheamento eleitoral não apresenta objetivos definidos. No entanto, ele não deixa de ser um elemento de denúncia, e uma potencial ameaça ao sistema político tal como está estruturado, se estiver associado a adesões numericamente significativas e organizadas em torno de uma proposta alternativa de organização social.

Independente desses possíveis desenvolvimentos, trata-se, sem dúvida, da expressão de um cenário de desigualdade de capacidades estruturais e cognitivas, e em segundo lugar, desmistifica a associação entre democracia ideal, horizontal e assembleísta, (grega ou rousseauniana) e democracias representativas contemporâneas (verticais e de distanciamento). Nesse sentido, o alheamento eleitoral deslegitima totalmente a tentativa de se estabelecer uma congruência entre teorias da democracia original ou "clássica" e o sistema representativo.

Assim, a legitimidade das democracias representativas concretiza o que José Guilherme Merquior chamou de legitimidade-crença, inspirada nos arquétipos de dominação e estabilidade propostos por Max Weber, enfocando a capacidade de condução do governo e a aceitação/confiança da população, e se distancia do que ele denominou legitimidade-poder, inspirada em Rousseau, e focada na política ativa e permanente de cidadãos altamente politizados e iguais (MERQUIOR, 1990).

Por último, o alheamento eleitoral indica que, uma vez consolidadas, as

\footnotetext{
${ }^{18}$ Como diria James Scott (1987), as armas dos fracos são fracas, e o alheamento eleitoral, de forma isolada, é uma arma fraca contra o sistema.
} 
instituições políticas andam por si mesmas, tendendo a ser auto-suficientes pelos sustentáculos da "legitimidade geral" ou "legitimação pelo procedimento", na definição de Luhmann, onde "a burocracia e o público estão (...) afastados um do outro. 0 que não quer dizer que os procedimentos que criam e declaram símbolos se encontrem no lugar errado e possam ser abandonados; mas eles desempenham uma outra função que isola temática e socialmente o indivíduo quando ele não está de acordo, de forma que os seus protestos não tenham conseqüências. Parece, pois, que uma legitimação pelo procedimento não consiste em comprometer internamente o interessado, mas sim em isolá-lo como fonte de problemas e em apresentar uma organização social como independente de seu acordo ou de sua rejeição" (LUHMANN, 1980, p. 103). A legitimidade geral torna-se autosuficiente, e os indivíduos acabam aceitando-na, mesmo se não compreendem seus significados.

A categoria de alheamento eleitoral pode ser usada no plano empírico para observar os níveis de participação das populações que adotam o modelo representativo com participação popular em eleições periódicas. Em países com sistema de voto facultativo, em geral observa-se a abstenção, mas isto não é uma regra. Pode-se supor que o voto nulo caracteriza um protesto não apenas contra candidatos, mas em especial contra a obrigatoriedade do voto, mas é necessário observar pesquisas e dados estatísticos e qualitativos para respaldar afirmações desta natureza.

Para estudos futuros, a categoria alheamento eleitoral pode ser um instrumento de análise de resultados tanto de eleições, como também das motivações das legislações de países de democracia eleitoral, afim de verificar o tratamento dispensado ao fenômeno. Neste sentido, já é possível antecipar uma certa desconstrução do conceito, pois na prática, as abstenções tendem a ser legalmente mais poderosas do que os votos em branco e nulos (que são, no Brasil ${ }^{19}$ e em outros países como os Estados Unidos, considerados inválidos, e portanto,

\footnotetext{
${ }^{19}$ No Brasil, votos em branco e votos nulos para cargos de Presidente da República e Governador de Estado eram considerados válidos até 1997, quando o então Presidente da República, Fernando Henrique Cardoso, submeteu e logrou aprovação do parlamento para a nova lei eleitoral 9504/97, cujo Artigo 20 exclui os votos em branco e votos nulos da esfera dos votos válidos, diminuindo assim o número de votos necessário para um possível segundo turno. Tal lei sofreu alterações por alguns decretos pelas leis 9840/99, 10408/02, 10.740/03 e 11.300/06, mas nenhuma delas altera 0 Artigo $2^{\circ}$, cujo texto diz claramente: "Será considerado eleito o candidato a Presidente ou a Governador que obtiver a maioria absoluta de votos, não computados os em branco e os nulos".
} 
incapazes de interferir na contagem - a abstenção, por vez, qualifica-se como dos elementos que interfere no quorum eleitoral, e desta forma é capaz de paralisar o processo).

\section{REFERÊNCIAS}

ALMOND, Gabriel e VERBA, Sidney. The civic culture. Boston: Little, Brown and Company Inc., 1965. . (ed). The civic culture revisited. Sage Publishings, 1989.

AVRITZER, Leonardo. Teoria crítica e teoria democrática: da impossibilidade da democracia ao conceito de esfera pública. Novos Estudos Cebrap, São Paulo, v. 53, p. 161-187, 1999.

. Sociedade civil, instituições participativas e representação: da autorização à legitimidade da ação". Dados, Rio de Janeiro, v. 50, p. 443-464, 2007.

BOBBIO, Norberto, MATTEUCCI, Nicolas e PASQUINO, Gianfranco.(orgs.), Dicionário de política, volumes 1 e 2, Brasília: Ed. UnB, 1995.

BOURDIEU, Pierre. Distinction: a social critique of the judgement of taste. Cambridge, Massachusetts, Harvard: University Press, 1984.

BOTTOMORE, Tom. (ed.) Dicionário do pensamento marxista. Rio de Janeiro: Jorge Zahar Editor, 1988.

BRETTON, Philippe. A incompetência democrática. São Paulo: Edições Loyola, 2006.

CHISHOLM, Robert. A ética feroz de Nicolau Maquiavel. In: QUIRINO, Célia Galvão; VOUGA; Claudio e BRANDÃO, Gido Marçal (orgs.). Clássicos do pensamento político moderno. São Paulo: Edusp, 1998.

COHN, Gabriel. Crítica e resignação: fundamentos da sociologia de Max Weber. São Paulo: T. A. Queiroz Editor, 1979.

COSTA PORTO, Walter. Dicionário do voto. Brasília: Ed. UnB, 2000.

CROZIER, Michel; HUNTINGTON, Samuel e WATANUKI, Joji. The crisis of democracy. New York: Columbia University Press, 1975.

DAHL, Robert. Poliarquia. São Paulo: Edusp, 1997.

DURKHEIM, Émile. O suicídio. São Paulo: Martins Fontes, 2000.

ELIASOPH, Nina. Avoiding politics: how Americans produce apathy in everyday

AlHeAmento ELEITORAL: ReFLEXÕES SOBRE O SIGNIFICADO DE VOTOS... 
life. Cambridge, Massachusetts: Cambridge University Press, 1998.

FINLEY, Moses I. Democracy ancient and modern. Piscataway, New Jersey: Rutgers University Press, 1985.

FLATHMAN, Richard E. Legitimacy. In: GOODIN, Robert e PETTIT, Philip. (eds.) A companion to contemporary political philosophy. Cambridge, Massachusetts: Blackwell Publishers, 1996.

GUTMANN, Amy. Democracy. In: GOODIN, Robert e PETTIT, Philip. (eds.) A companion to contemporary political philosophy. Cambridge, Massachusetts: Blackwell Publishers, 1996.

HIRSCHMAN, Albert 0. De consumidor a cidadão: atividade privada e participação na vida pública. São Paulo: Brasiliense, 1983.

LEVI, Lucciano. Verbete "Legitimidade". In: BOBBIO, Norberto, MATTEUCCI, Nicolas e PASQUINO, Gianfranco.(orgs.), Dicionário de política, volumes 1 e 2, Brasília: Ed. UnB, 1995.

LIPSET, Seymour Martin. Political man: the social basis of politics. Garden City, New York: Doubleday \& Company, Inc, 1960.

LUHMANN, Niklas. Legitimação pelo procedimento. Brasília: Ed. UnB, 1980.

MACPHERSON, Crawford B. A democracia liberal: origens e evolução. Rio de Janeiro: Zahar Editores, 1978.

MERQUIOR, José Guilherme. Rousseau e Weber: dois estudos sobre a teoria da legitimidade. Rio de Janeiro: ed. Guanabara, 1990.

MIGUEL, Luis Felipe. Um ponto cego nas teorias de democracia: os meios de comunicação. Revista BIB (ANPOCS), número 49, pp. 51-78, Rio de Janeiro, Relume-Dumará, $1^{\circ}$ semestre de 2000.

MOUFFE, Chantal. On the political. Nova York: Routledge, 2005.

. O regresso do político. Lisboa: Gradiva, 1992.

PATEMAN, Carole. Participação e teoria democrática. Rio de Janeiro: Paz e Terra, 1992.

PIZZORNO, Alessandro. Introdución al estudio de la participación política. In: PIZZORNO, Alessandro; KAPLAN, Marcos e CASTELLS, Manuel. Participacion y cambio social en la problematica contemporânea. Buenos Aires: Siap-Planteos, 1975.

POWER, Timothy e GARNAND, James C. Determinants of invalid voting in Latin 
America. www.sciencedirect.com, janeiro, 2007.

PUTNAM, Robert D. Comunidade e democracia: a experiência da Itália moderna. Rio de Janeiro: FGV, 1997.

RANIERI, Jesus. A câmara escura, São Paulo, Boitempo, 2001.

REIS, Fábio Wanderley. Política e racionalidade: problemas de teoria e método de uma sociologia crítica da política. Belo Horizonte: UFMG/PROED/RBEP, 1984. SANTOS, Wanderley Guilherme. A lógica-dual da ação coletiva. Dados, Rio de Janeiro, v. 32, n. 1, 1989.

. Paradoxos do Voto. Revista Brasileira de Ciências Sociais, n. 20, 1992. . Poliarquia em 3-D: notas para uma revisão teórica. Dados, Rio de Janeiro, v. 41, n. 2, 1998.

SARTORI, Giovanni. A teoria da democracia revisitada, volume 1, São Paulo: Ed. Ática, 1987.

SCHUMPETER, Joseph A. Capitalism, socialism and democracy. New York: Harper Collins Publishers, 2002.

SCOTT, James C. Weapons of the weak: everyday forms of peasant resistance. London: Yale University Press, 1987.

SOUZA, Jessé. (org.) A atualidade de Max Weber. Brasília: Ed. UnB, 2000.

TOCQUEVILLE, Alexis. A democracia na América. Belo Horizonte: Itatiaia, 1987.

WEBER, Max. Conceitos básicos de sociologia, São Paulo: Editora Moraes, 1989. 